\title{
Chest Wall Mobility Is Related to Respiratory Muscle Strength and Lung Volumes in Healthy Subjects
}

\author{
Fernanda de Cordoba Lanza PhD, Anderson Alves de Camargo PT MSc, Lilian Rocha Ferraz Archija, \\ Jessyca Pachi Rodrigues Selman, Carla Malaguti PT PhD, and Simone Dal Corso PT PhD
}

\begin{abstract}
BACKGROUND: Chest wall mobility is often measured in clinical practice, but the correlations between chest wall mobility and respiratory muscle strength and lung volumes are unknown. We investigate the associations between chest wall mobility, axillary and thoracic cirtometry values, respiratory muscle strength (maximum inspiratory pressure and maximum expiratory pressure), and lung volumes (expiratory reserve volume, $F_{E V}$, inspiratory capacity, $F_{E V} / F V C$ ), and the determinants of chest mobility in healthy subjects. METHODS: In 64 healthy subjects we measured inspiratory capacity, $\mathrm{FVC}, \mathrm{FEV}_{1}$, expiratory reserve volume, maximum inspiratory pressure, and maximum expiratory pressure, and chest wall mobility via axillary and thoracic cirtometry. We used linear regression to evaluate the influence of the measured variables on chest wall mobility. RESULTS: The subjects' mean \pm SD values were: age $24 \pm 3$ years, axillary cirtometry $6.3 \pm 2.0 \mathrm{~cm}$, thoracic cirtometry $7.5 \pm 2.3 \mathrm{~cm}$; maximum inspiratory pressure $90.4 \pm 10.6 \%$ of predicted, maximum expiratory pressure $92.8 \pm 13.5 \%$ of predicted, inspiratory capacity $99.7 \pm 8.6 \%$ of predicted, FVC $101.9 \pm 10.6 \%$ of predicted, $\mathrm{FEV}_{1} \mathbf{9 8 . 2} \pm 10.3 \%$ of predicted, expiratory reserve volume $90.9 \pm 19.9 \%$ of predicted. There were significant correlations between axillary cirtometry and FVC $(r=0.32), \mathrm{FEV}_{1}(\mathrm{r}=0.30)$, maximum inspiratory pressure $(\mathrm{r}=0.48)$, maximum expiratory pressure $(r=0.25)$, and inspiratory capacity $(r=0.24)$, and between thoracic cirtometry and $\mathrm{FVC}(\mathrm{r}=\mathbf{0 . 5 0}), \mathrm{FEV}_{1}(\mathrm{r}=\mathbf{0 . 4 8})$, maximum inspiratory pressure $(\mathrm{r}=0.46)$, maximum expiratory pressure $(r=0.37)$, inspiratory capacity $(r=0.39)$, and expiratory reserve volume $(r=0.47)$. In multiple regression analysis the variable that best explained the axillary cirtometry variation was maximum inspiratory pressure $\left(R^{2} 0.23\right)$, and for thoracic cirtometry it was $F V C$ and maximum inspiratory pressure $\left(R^{2} \mathbf{0 . 3 2}\right)$. CONCLUSIONS: Chest mobility in healthy subjects is related to respiratory muscle strength and lung function; the higher the axillary cirtometry and thoracic cirtometry values, the greater the maximum inspiratory pressure, maximum expiratory pressure, and lung volumes in healthy subjects. Key words: physical therapy; lung function tests; respiratory muscles; muscle strength; thorax wall; respiratory mechanics. [Respir Care 2013;58(12): 2107-2112. (c) 2013 Daedalus Enterprises]
\end{abstract}

\section{Introduction}

In clinical practice, respiratory muscle function is evaluated with maximum inspiratory pressure and maximum

\footnotetext{
Dr Lanza, Ms Archija, and Ms Selman are affiliated with the School of Physiotherapy, Department of Health; and Mr de Camargo, and Dr Dal Corso are affiliated with the Postgraduate Program in Rehabilitation Sciences Master's Program, Universidade Nove de Julho, São Paulo, Brazil. Dr Malaguti is affiliated with the Physiology Department, Federal University of Juiz de Fora, Juiz de Fora, Minas Gerais, Brazil.
}

Mr de Camargo was supported by a scientific institution scholarship from expiratory pressure. These pressures generated by the inspiratory and expiratory muscles, respectively, are respon-

\footnotetext{
Programa de Suporte da Pós Graduação de Instituições de Ensino Particulares, da Coordenação de Aperfeiçoamento de Pessoal de Nível Superior, São Paulo, São Paulo, Brazil. Ms Archija and Ms Selman were supported by scientific institution scholarships from Fundação de Amparo à Pesquisa do Estado de São Paulo, São Paulo, Brazil.

Dr Lanza presented a version of this paper at the 16th International Symposium of Respiratory and Intensive Care Physical Therapy, held May 14, 2012, in Rio De Janeiro, Brazil.
} 
sible for volume changes in the respiratory system. ${ }^{1}$ Based on the pressure-volume relationship of the respiratory system, the higher maximum inspiratory pressure is achieved when the inspiration starts from the lowest lung volume (residual volume), and vice versa. Therefore, the stronger the respiratory muscles, the higher the pulmonary volume. ${ }^{2}$ In accordance with this reasoning, Enright et al found an increase in the vital capacity and total lung capacity after training the respiratory muscles in healthy subjects. ${ }^{3}$ The same was observed in patients with cystic fibrosis. $^{4}$

Along with the lungs, the chest wall is an elastic structure and follows the displacement of the lungs. Measurement of the thoracic movement, from the total lung capacity to residual volume, with a measuring tape has been used as a chest wall mobility index in healthy subjects ${ }^{5}$ and patients with asthma, ${ }^{6}$ ankylosing spondylitis, ${ }^{7}$ fibromyalgia, ${ }^{8}$ COPD,${ }^{9,10}$ and osteoporosis. ${ }^{11}$

Two previous studies found a significant relationship between chest expansion and maximum inspiratory pressure and maximum expiratory pressure, which ranged from 0.37 to $0.57,8,11$ and 2 other studies showed a correlation between chest expansion and vital capacity ${ }^{7}$ and inspiratory capacity. ${ }^{9}$ However, there have been no studies of the correlation between respiratory muscle strength, pulmonary volumes, and chest expansion, nor the determinants of chest expansion in healthy subjects. We studied the relationship between chest wall mobility, respiratory muscle strength, and pulmonary volumes, and the determinants of chest wall mobility.

\section{Methods}

This prospective study was performed in the clinical exercise physiology laboratory of the University Nove de Julho, São Paulo, Brazil. Healthy subjects (normal lung function tests, no acute or chronic respiratory diseases, no cardiovascular diseases) aged 20-30 years old were included. We excluded people who could not perform the tests or had chest wall deformities or respiratory or neurologic diseases. Written informed consent was obtained from all subjects, and the local ethics committee approved the study (370562).

\footnotetext{
The authors have disclosed no conflicts of interest.

Correspondence: Fernanda de Cordoba Lanza PhD, Universidade Nove de Julho, School of Physiotherapy, Department of Health, Rua Vergueiro, 235/239, Bairro Liberdade 01504001 São Paulo, SP, Brazil. Email: lanzafe@gmail.com.
}

DOI: $10.4187 /$ respcare.02415

\section{QUICK LOOK}

\section{Current knowledge}

Respiratory muscle function is commonly measured as the maximum inspiratory and expiratory pressures. These pressures, generated by the inspiratory and expiratory muscles, are responsible for volume changes in the respiratory system.

\section{What this paper contributes to our knowledge}

Chest wall mobility in healthy subjects correlated with respiratory muscle strength and lung function. Higher chest wall mobility was associated with greater maximum inspiratory and expiratory pressures, forced vital capacity, and inspiratory capacity.

\section{Spirometry}

Spirometry was performed with a calibrated pneumotachograph (CPFS/D USB, Medical Graphics, St Paul, Minnesota). The technical procedures and the acceptability and reproducibility criteria were as recommended by the American Thoracic Society. ${ }^{12}$ All the subjects completed at least 3 acceptable maximum forced expiratory maneuvers. We recorded $\mathrm{FVC}, \mathrm{FEV}_{1}, \mathrm{FEV}_{1} / \mathrm{FVC}$, and slow vital capacity to measure inspiratory capacity and expiratory reserve volume. The measurements were compared with the predicted values from Pereira ${ }^{13}$ for Brazilian adults.

\section{Anthropometry}

Body mass was measured to the nearest $0.1 \mathrm{~kg}$, using a calibrated balance (110F, Welmy, São Paulo, Brazil), and body height was determined to the nearest $0.5 \mathrm{~cm}$, using a stadiometer. Body mass index was calculated as the ratio of weight to height in meters squared.

\section{Chest Wall Mobility}

During the chest wall mobility measurements the subject stood with hands on the hips. The cirtometry consisted of measuring the chest circumference with a measuring tape at 2 levels: the anterior axillary line (axillary cirtometry) and the tip of the xiphoid process (thoracic cirtometry). The standardized measurement procedure was to keep the 0 point of the tape fixed on the midline of the body, horizontally aligned with the landmarks, while the other end of the tape was allowed to move. The tape was snug but not tight, so that the soft-tissue contours remained unchanged. For both the thoracic and axillary measurements the subjects were asked to perform maximum in- 
spiration and expirations twice, and to hold the maximum inspiration or expiration for at least 2 seconds, during which the measurements were taken, as previously described. ${ }^{14}$ All the measurements were done by the same trained observer.

\section{Maximum Respiratory Pressures}

Maximum inspiratory pressure, followed by maximum expiratory pressure, was obtained starting at residual volume or total lung capacity, respectively, with the subject seated, wearing a nose clip, and with a rigid, plastic, flanged mouthpiece. The subject was connected to a manual shutter apparatus, and the pressures were measured with a aneroid manometer $\left(120 \mathrm{~cm} \mathrm{H}_{2} \mathrm{O}\right.$, GerAr, São Paulo, Brazil). A small leak was introduced between the occlusion and the mouth to prevent glottic closure, and the subject held his or her cheeks with one hand during the maneuver. Inspiratory or expiratory effort was sustained for at least $1 \mathrm{~s}$. Each subject performed 5 acceptable and reproducible maximum maneuvers (ie, differences of $\leq 10 \%$ between values). We recorded the highest values. ${ }^{15}$ The maximum pressures are expressed as absolute values and percent-ofpredicted, based on Brazilian values. ${ }^{16}$

\section{Statistical Analysis}

The normality of the data was assessed with the Kolmogorov-Smirnov test. The variables are expressed as mean $\pm \mathrm{SD}$. The following variables were correlated with the Pearson correlation analysis: chest wall mobility, maximum respiratory pressure, FVC, $\mathrm{FEV}_{1}$, inspiratory capacity, and expiratory reserve volume. Correlation was considered weak if $r$ was $<0.50$, moderate if $r$ was 0.50 0.70 , and good if $\mathrm{r}$ was $>0.70$. Linear regression analysis was used to evaluate the influence of some variables on chest wall mobility. $P<.05$ was considered significant. Statistical tests were done with statistics software (SPSS 14.0, SPSS, Chicago, Illinois).

\section{Results}

We recruited 71 subjects, but 5 were excluded because they could not correctly perform the maneuvers, and 2 were excluded because spirometry indicated obstruction. Thus, we analyzed data from 64 subjects ( 34 men), all of whom had maximum respiratory pressure within the normal range, based on Brazilian values. ${ }^{16}$ The baseline characteristics of anthropometry and spirometry are presented in Table 1.

The axillary cirtometry significantly correlated with maximum inspiratory pressure $(\mathrm{r}=0.48, P<.001)$, as did thoracic cirtometry and maximum inspiratory pressure ( $\mathrm{r}=0.46, P<.001$, Figure). The axillary cirtometry and
Table 1. Maximum Respiratory Pressures, Cirtometry, and Pulmonary Function Test Results From 64 Healthy Brazilian Subjects

\begin{tabular}{|c|c|}
\hline Male/female, no. & $34 / 30$ \\
\hline Age, y & $24 \pm 3$ \\
\hline Body mass index, $\mathrm{kg} / \mathrm{m}^{2}$ & $24.1 \pm 5.3$ \\
\hline Maximum inspiratory pressure, $\mathrm{cm} \mathrm{H}_{2} \mathrm{O}$ & $-93.8 \pm 30.2$ \\
\hline Maximum inspiratory pressure, $\%$ of predicted & $90.4 \pm 10.6$ \\
\hline 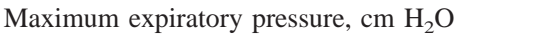 & $103.2 \pm 38.1$ \\
\hline Maximum expiratory pressure, $\%$ of predicted & $92.8 \pm 13.5$ \\
\hline Axillary cirtometry, $\mathrm{cm}$ & $6.3 \pm 2.0$ \\
\hline Thoracic cirtometry, $\mathrm{cm}$ & $7.5 \pm 2.3$ \\
\hline FVC, L & $4.4 \pm 0.9$ \\
\hline $\mathrm{FVC}, \%$ of predicted & $101.9 \pm 10.6$ \\
\hline $\mathrm{FEV}_{1}, \mathrm{~L}$ & $3.7 \pm 0.7$ \\
\hline $\mathrm{FEV}_{1}, \%$ of predicted & $98.2 \pm 10.3$ \\
\hline $\mathrm{FEV}_{1} / \mathrm{FVC}$ & $86.5 \pm 6.9$ \\
\hline Inspiratory capacity, L & $2.8 \pm 0.7$ \\
\hline Inspiratory capacity, $\%$ of predicted & $99.7 \pm 8.6$ \\
\hline Expiratory reserve volume, $\mathrm{L}$ & $1.5 \pm 0.3$ \\
\hline Expiratory reserve volume, $\%$ of predicted & $90.9 \pm 19.9$ \\
\hline values a & \\
\hline
\end{tabular}

thoracic cirtometry showed significant weak correlation with maximum expiratory pressure: axillary cirtometry vs maximum expiratory pressure $\mathrm{r}=0.25, P=.047$; thoracic cirtometry vs maximum expiratory pressure $\mathrm{r}=0.37$, $P=.003$.

Chest wall mobility correlated with lung capacities. Axillary cirtometry was significantly correlated with inspiratory capacity $(\mathrm{r}=0.24, P=.012)$, but not with expiratory reserve volume $(\mathrm{r}=0.31, P=.057)$. Thoracic cirtometry correlated with both inspiratory capacity $(\mathrm{r}=0.39, P=.02)$ and expiratory reserve volume $(\mathrm{r}=0.47, P<.001)$ (see the Figure).

Correlation between thoracic cirtometry and FVC was moderate $(\mathrm{r}=0.50, P<.001)$, and between thoracic cirtometry and $\mathrm{FEV}_{1}$ was weak $(\mathrm{r}=0.48, P<.001)$. Although significant, those correlations are not excellent (Table 2). Correlation was also weak between axillary cirtometry and FVC $(\mathrm{r}=0.32, P=.009)$ and $\mathrm{FEV}_{1}$ $(\mathrm{r}=0.30, P=.02)$.

In linear regression, maximum inspiratory pressure was the variable associated with axillary cirtometry $\left(R^{2} 0.23\right.$, $P<.001)$. FVC and maximum inspiratory pressure were both associated with thoracic cirtometry $\left(\mathrm{R}^{2} 0.32, P<.001\right)$.

\section{Discussion}

We found correlations between chest wall mobility, respiratory muscle strength, and lung function in healthy subjects. After linear regression analysis, maximum inspiratory pressure was the variable that best correlated 

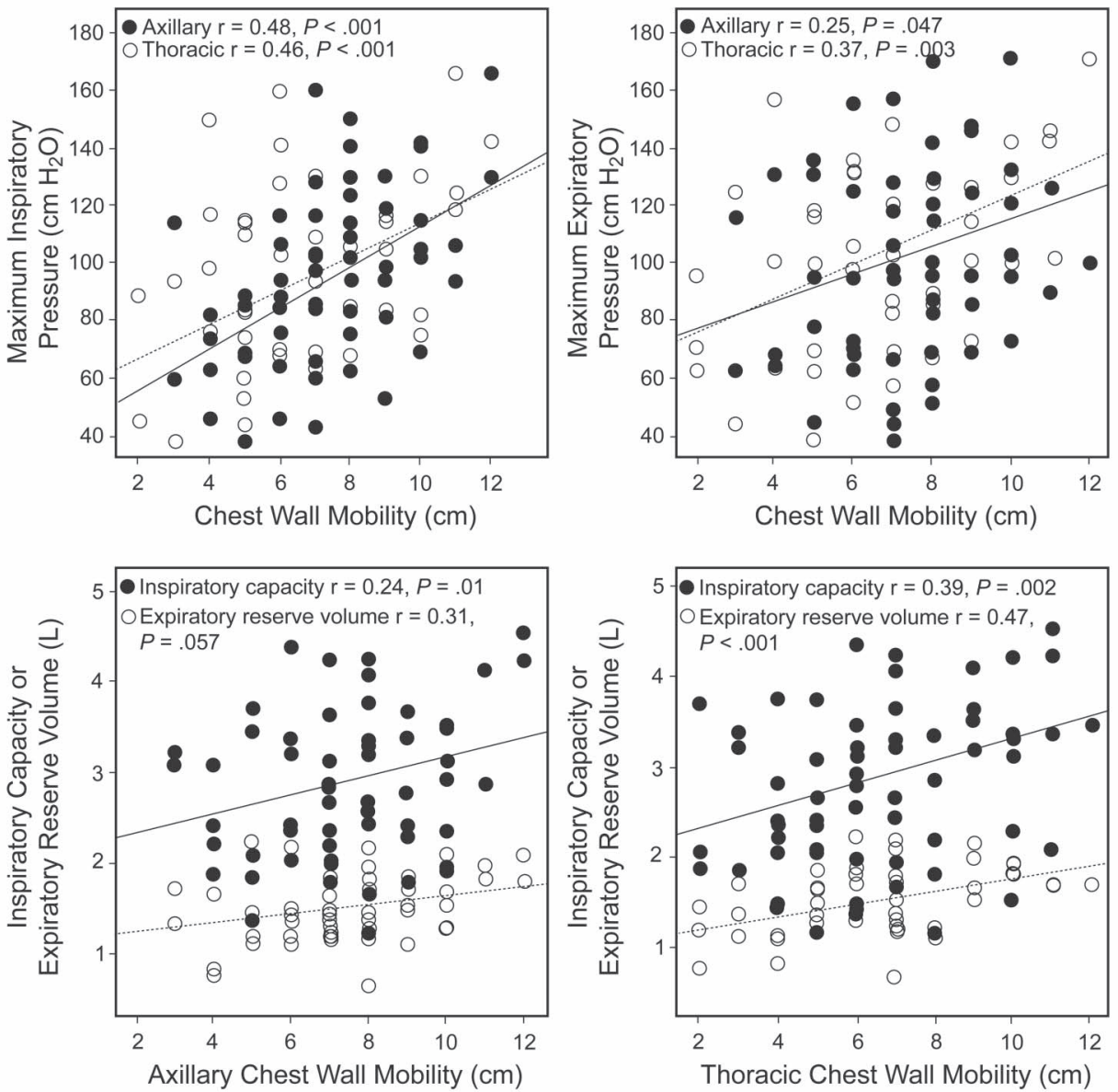

Figure. Correlation between axillary cirtometry measurements, thoracic cirtometry measurements, maximum inspiratory pressure, maximum expiratory pressure, inspiratory capacity, and expiratory reserve volume.

Table 2. Correlations Between Axillary Cirtometry, Thoracic Cirtometry, FVC, and FEV 1

\begin{tabular}{lccc}
\hline \hline & & FVC & FEV $_{1}$ \\
\hline Axillary cirtometry & $\mathrm{r}$ & 0.32 & 0.30 \\
& $P$ & .009 & .02 \\
Thoracic cirtometry & $\mathrm{r}$ & 0.50 & 0.48 \\
& $P$ & $<.001$ & $<.001$ \\
\hline
\end{tabular}

with axillary cirtometry. Maximum inspiratory pressure and FVC best correlated with thoracic cirtometry.

Axillary cirtometry and thoracic cirtometry significantly correlated with FVC ( $\mathrm{r}=0.32, \mathrm{r}=0.50$, respectively). Significant correlations were also found between chest wall mobility, $\mathrm{FEV}_{1}$, and inspiratory capacity: axillary cirtometry vs $\mathrm{FEV}_{1} \mathrm{r}=0.30$; thoracic cirtometry vs $\mathrm{FEV}_{1} \mathrm{r}=0.48$; axillary cirtometry vs inspiratory capacity $r=0.24$; thoracic cirtometry vs inspiratory capacity $\mathrm{r}=0.39$. Until now it was not clear if chest wall mobility was associated with lung volumes in healthy subjects. We found that the greater the volume, the greater the chest wall mobility. To our knowledge, this is the first study of this correlation, although it is very justifiable from the standpoint of respiratory mechanics in subjects without cardiopulmonary diseases. Similar observations were made by Malaguti et al in COPD patients, in whom there was a positive correlation between inspiratory capacity and abdominal chest wall mobility. ${ }^{9}$ They found no correlation between other lung function variables $\left(\mathrm{FEV}_{1}\right.$ and $\left.\mathrm{FVC}\right)$ and other axillary or thoracic cirtometry, which is explained by the reduced chest wall mobility of COPD patients. Reduced chest wall mobility in patients with chronic lung disease has also been observed by other authors. ${ }^{6,10}$

Expiratory reserve volume significantly correlated with thoracic cirtometry $(\mathrm{r}=0.47, P<.001)$, but not with axillary cirtometry $(\mathrm{r}=0.37, P=.057)$ in our study, although there was a tendency. We speculate that this occurred due to respiratory muscles being recruited during the expiratory reserve volume maneuver. The expiratory muscles have their insertions on the lower rib cage, which reduces the chest diameter during the expiratory reserve volume maneuver, accumulating elastic energy and facil- 
itating further expansion in the next inspiration, which increases chest wall mobility. We found no studies of that correlation. Knook et al suggest that the reduced respiratory muscle strength in children with juvenile arthritis decreases their expiratory reserve volume, and, consequently, FVC, which indicates worsening chest wall mobility. ${ }^{17}$

Similar to lung volumes, respiratory muscle strength was related to chest wall mobility in our study. The positive correlation between axillary cirtometry, thoracic cirtometry, and maximum inspiratory pressure $(\mathrm{r}=0.48$, $\mathrm{r}=0.46$, respectively) is expected, since the greater the inspiratory muscle strength, the greater the expansion of both the upper and the lower rib cage. Such correlation was also observed in diseases other than respiratory disease. Çimen et al found significant correlation between the respiratory muscle strength and axillary cirtometry $(r=0.37)$ in women with osteoporosis. ${ }^{11}$ In patients with fibromyalgia, chest wall mobility correlated with maximum inspiratory pressure and maximum expiratory pressure $(r=0.49, r=0.51$, respectively); those values are similar the values we observed in the present study. ${ }^{8}$ But Sahin et al found no significant correlation between chest wall mobility, maximum inspiratory pressure, and maximum expiratory pressure $(\mathrm{r}=0.10, \mathrm{r}=0.09)$ in women with fibromyalgia. ${ }^{18}$ They explain that result as due to pain and muscle fatigue in those patients, which reduces respiratory muscle strength and, hence, chest wall mobility. It is not possible to explore more specifically the results from Sahin et al, but we believe that linear correlation probably was not observed, because different pain intensity can result in different muscles activity.

The correlation between chest wall mobility and maximum expiratory pressure, although significant, was weak. It was expected that maximum expiratory pressure would have worse correlation with chest wall mobility than would maximum inspiratory pressure. This is explained by the fact that because chest wall mobility is greater, the diaphragm's effort during the inspiratory phase is stronger. The same does not happen during the expiratory phase, during which mobility is not related to expiratory muscle effort.

All the correlations between muscle strength and chest wall mobility in the present study were weak, though statically significant. We believe that other factors, such as elastic recoil, can contribute in all those correlations. Lung volumes are related not only to respiratory muscle strength but also to the compliance and resistance of the respiratory system. We studied healthy subjects; however, even in healthy subjects, not only muscle strength but also the physiological mechanism influences the lung volumes. Similar findings were made by other investigators in patients with respiratory and musculoskeletal diseases, ${ }^{18-21}$ after a rehabilitation program. ${ }^{22,23}$
We performed linear regression analysis to determine which variable could best explain the chest wall mobility variation. For axillary cirtometry, maximum inspiratory pressure was the variable that best explained the variation $\left(\mathrm{R}^{2} 0.23, P<.001\right)$. To our knowledge, this is the first time this result has been described. Even though axillary cirtometry may be associated with lung volumes, the inspiratory muscle strength is the most important factor. In a series of studies, Enright et al reported that high intensity respiratory muscle training ( $80 \%$ of maximum inspiratory pressure) increased maximum inspiratory pressure, vital capacity, and total lung capacity in healthy subjects ${ }^{3,24}$ and in patients with cystic fibrosis. ${ }^{4}$ Although Enright et al have not described the correlation between those variables, we expected a positive correlation between them, corroborating our finding that respiratory muscle strength is related to the circumference and, consequently, to lung volume.

Maximum inspiratory pressure and FVC were both associated with thoracic cirtometry in the linear regression $\left(\mathrm{R}^{2} 0.32, P<.001\right)$. The same justifications previously fit for axillary cirtometry must be considered; however, permanence of FVC can be explained. During the FVC maneuver there is great movement of the rib cage, more pronounced on the last ribs, because there is greater mobility of the thoracic cage in this area.

\section{Limitations}

We did not use the gold standard method for chest wall mobility evaluation (optoelectronic plethysmography ${ }^{25}$ ), because that method requires highly trained personnel for both the data collection and interpretation. Our method of measuring thoracic mobility seems to be an adequate and simpler alternative for clinical practice. Abdominal cirtometry was not included in this study, although it has been evaluated, since, in most of the individuals, when they were asked to take a deep inspiration, the movement was opposite to that observed on the abdomen in a quiet breath. A similar finding was described by Basso et al. ${ }^{6}$ Thus, this variable was excluded from the analysis due to inconsistency in its evaluation. We believe there was no bias in the present results, since most studies have assessed chest mobility at the axillary and xiphoid process levels, as we did.

Based on our data, our method of measuring chest wall mobility is a useful alternative when optoelectronic plethysmography is not available, and can provide information about the interaction of the components of the respiratory system (respiratory muscles and lung volumes). ${ }^{25}$ Our results can help clinical practice, as a tool for the interpretation of respiratory muscle performance. Based on this study, we can infer the interaction between chest wall mobility, lung volumes, and respiratory muscles. Chest 
wall cirtometry can also be used for monitoring patients with various diseases, because it is easy to perform, its improvement after training is expected, and it reflects lung volumes and respiratory muscle strength.

\section{Conclusions}

Chest mobility in healthy subjects correlates with respiratory muscle strength and lung function. The larger the axillary and thoracic cirtometry measurement, the greater the maximum inspiratory pressure, maximum expiratory pressure, $\mathrm{FVC}, \mathrm{FEV}_{1}$, and inspiratory capacity.

\section{REFERENCES}

1. Gibson GJ. Lung volumes and elasticity. In: Hughes JM, Pride NB, editors. Lung function tests: physiological principles and clinical applications. Michigan: Saunders; 1999:45-56.

2. George RB, Light RW, Matthay MA, Matthay RA. Chest medicine: essential of pulmonary and critical care medicine, 5th edition. New York: Lippincott Williams \& Wilkins; 2005.

3. Enright SJ, Unnithan VB. Effect of inspiratory muscle training intensities on pulmonary function and work capacity in people who are healthy: a randomized controlled trial. J Physiother 2011;91(6):894905.

4. Enright S, Chatham K, Ionescu AA, Unnithan VB, Shale DJ. Inspiratory muscle training improves lung function and exercise capacity in adults with cystic fibrosis. Chest 2004;126(2):405-411.

5. Bockenhauer SE, Chen H, Julliard KN, Weedon J. Measuring thoracic excursion: reliability of the cloth tape measure technique. J Am Osteopath Assoc 2007;107(5):191-196.

6. Basso RP, Regueiro EMG, Jamami M, Di Lorenzo VAP, Costa D. Relationship of the measure of the amplitude thoracoabdominal in asthmatics and healthy adolescents with the physical performance. Fisioter Mov 2011;24(1):107-114. Article in Portuguese.

7. Fisher LR, Cawley MI, Holgate ST. Relationship between chest expansion, pulmonary function, and exercise tolerance in patients with ankylosing spondylitis. Ann Rheum Dis 1990;49(11):921-925.

8. Ozgocmen S, Cimen OB, Ardicoglu O. Relationship between chest expansion and respiratory muscle strength in patients with primary fibromyalgia. Clin Rheumatol 2002;21(1):19-22.

9. Malaguti C, Rondelli RR, Souza LM, Domingues M, Dal Corso S. Reliability of chest wall mobility and its correlation with pulmonary function in patients with chronic obstructive pulmonary disease. Respir Care 2009;54(12):1703-1711.

10. Paulin E, Brunetto AF, Carvalho CRF. Efeitos de programa de exercícios físicos direcionado ao aumento da mobilidade torácica em pacientes portadores de doença pulmonar obstrutiva crônica. J Pneumol 2003;29(5):287-294. Article in Portuguese.

11. Çimen OB, Ulubas B, Salin G, Çalikogen M, Bagis S, Erdogon C. Pulmonary function tests, respiratory muscle strength, and endurance of patients with osteoporosis. South Med J 2003;96(5):423-426.

12. American Thoracic Society. Standardization of spirometry, 1994 update. Am J Respir Crit Care Med 1995;152(3):1107-1136.

13. Pereira CA. Espirometria. Diretrizes para testes de função pulmonar. J Bras Pneumol 2002;28:S1-S82. Article in Portuguese.

14. Kakizaki F, Shibuya M, Yamazaki T, Yamada M, Suzuki H, Homma I. Preliminary report on the effects of respiratory muscle stretch gymnastics on chest wall mobility in patients with chronic obstructive pulmonary disease. Respir Care 1999;44(4):409-414.

15. ATS/ERS Statement on Respiratory Muscle Testing. Am J Respir Crit Care Med 2002;166(4)518-624.

16. Neder JA, Andreoni S, Lerario MC, Nery LE. Reference values for lung function tests. II. Maximal respiratory pressures and voluntary ventilation. Braz J Biol Res 1999;32(6):719-727.

17. Knook LM, de Kleer IM, van der Ent CK, van der Net JJ, Prakken BJ, Kuis W. Lung function abnormalities and respiratory muscle weakness in children with juvenile chronic arthritis. Eur Respir J 1999;14(3):529-533.

18. Sahin G, Ulubas B, Çalikoglu M, Çime OB, Erdogan C. Is chest expansion a determinant of pulmonary muscle strength in primary fibromyalgia? Joint Bone Spine 2004;71(2):140-143.

19. Sahin G, Ulubaş B, Calikoğlu M, Erdoğan C. Handgrip strength, pulmonary function tests, and pulmonary muscle strength in fibromyalgia syndrome: is there any relationship? South Med J 2004; 97(1):25-29.

20. Romagnoli I, Gorini M, Gigliotti F, Bianchi R, Lanini B, Grazzini $\mathrm{M}$, et al. Chest wall kinematics, respiratory muscle action and dyspnoea during arm vs leg exercise in humans. Acta Physiol 2006; 188(1):63-73.

21. Aliverti A, Stevenson N, Dellaca RL, Mauro AL, Pedotti A, Calverley PM. Regional chest wall volumes during exercise in chronic obstructive pulmonary disease. Thorax 2004;59(3):210-216.

22. Silva EM, Andrade SC, Vilar MJ. Evaluation of the effects of Global Postural Reeducation in patients with ankylosing spondylitis. Rheumatol Int 2012;32(7):2155-2163.

23. Gyurcsik ZN, Abdrás A, Bodnár N, Szekanecz Z, Szántó S. Improvement in pain intensity, spine stiffness, and mobility during a controlled individualized physiotherapy program in ankylosing spondylitis. Rheumatol Int 2012;32(12):3931-3936.

24. Enright SJ, Unnithan VB, Heward C, Withnall L, Davies DH. Effect of high-intensity inspiratory muscle training on lung volumes, diaphragm thickness, and exercise capacity in subjects who are healthy. Phys Ther 2006;86(3):345-354.

25. Layton AM, Moran SL, Garber CE, Armstrong HF, Basner RC, Thomashow BM, Bartels MN. Optoelectronic plethysmography compared to spirometry during maximal exercise. Respir Physiol Neurobiol 2013;185(2):362-368. 